\title{
PEREKAT KAYU LAPIS DARI DAUN LAMTORO (Leucaena Leucocephala)
}

\author{
Meldia Fitri, \\ Program Studi Teknik Industri Sekolah Tinggi Teknik Industri (STTIND) Padang \\ Email: meldia.ananda@yahoo.com
}

\begin{abstract}
Adhesives ( adesive) is a very important material in the plywood industry, the amount of adhesives commonly used in the industry is an adhesive containing chemicals Urea formaldehyde. Urea Formaldehyde is a chemical compound which, when exposed to heat slightly will cause emissions which produce toxic gases that can pollute the air and cause health problems, can cause respiratory irritation and may even cause cancer. As a substitute for urea formaldehyde can be used natural materials containing tannin, tannin is widely available in a variety of plants, tannin present in the stems, bark, leaves and roots of plants. Manufacture of plywood adhesive of the leaf lamtoro besides environmentally friendly, can also increase the economic value of the leaves lamtoro. The process of making plywood adhesive of the leaf lamtoro by means of extraction with water at a temperature of $70{ }^{\circ} \mathrm{C}$ for $2-5$ hours, the adhesive quality test results are as follows : pH 6.8 ; Viscosity (thickness) $1973.72 \mathrm{cps}$, density $1.0761 \mathrm{~g} / \mathrm{ml}$; Test appearance ( color adhesive greenish brown, the smell is not overpowering ; does not appear any other materials that affect the adhesive ; content of $21.77 \%$ solids ; gelatinasi time 39 minutes; strong bonding strength; the shelf life of one month. The cost of production of plywood adhesives of leaves lamtoro Rp.20.788.322 - with a production capacity of $1100 \mathrm{~kg}$, in order to obtain the production cost of Rp.18 898,- / $\mathrm{kg}$ sticking plywood of leaves lamtoro .
\end{abstract}

Keywords: Adhesives, Leaf lamtoro, manufacturing process, quality, cost of production.

\section{Pendahuluan}

Lamtoro sering disebut juga petai cina atau petai selong merupakan tanaman sejenis perdu dari suku Fabaceae (= Legumminosae, polong-polongan), yang sering digunakan dalam penghijauan lahan atau pencegahan erosi. Nama ilmiahnya leucocephala (berkepala putih) berasal dari kata leu artinya putih dan cephala artinya kepala, mengacu kepada bokol-bokol bunganya yang berwarna keputihan.

Daun lamtoro (Leucaena leucocephala (Lam de Wit) digunakan oleh masyarakat sebagai pakan ternak, sedangkan bijinya digunakan untuk lalapan saat makan ataupun sebagai campuran berbagai makanan. Di daerah Jawa Tengah, biji lamtoro (Leucaena leucocephala (Lam de Wit digunakan sebagai campuran "bothok". Batang lamtoro (Leucaena leucocephala (Lam de Wit.) dapat digunakan untuk membuat furniture atau dikumpulkan sebagai kayu bakar.

Akar lamtoro mengandung bitil akar sehingga memiliki potensi besar untuk memperbaiki kesuburan tanah (Kustiawan, 2001).
Lamtoro mengandung mimosin sebesar 3-5 \% BK, juga mengandung zat anti nutrisi lainnya termasuk protease inhibitor, tanin dan galactomannaan. Daun-daun lamtoro juga sering digunakan sebagai mulsa dan pupuk hijau. Daun-daun lamtoro lekas mengalami dekomposisi.Lamtoro diketahui menghasilkan zat penyamak dan zat pewarna merah, coklat dan hitam dari pepagan (kulit batang), daun dan polongnya. Kandungan senyawa tanin yang terkandung dalam daun lamtoro dapat digunakan sebagai perekat dalam proses perekatan kayu lapis.

Perekat merupakan bahan utama dalam industri pengolahan kayu khususnya komposit. Dari total biaya produksi kayu yang dibuat dalam berbagai bentuk dan jenis kayu komposit, lebih dari $32 \%$ adalah biaya perekatan. Perekat yang umum digunakan pada industri pengolahan kayu di Indonesia adalah urea formaldehida (UF) yang menghasilkan emisi formaldehida, yaitu gas beracun yang bisa menimbulkan penyakit. Emisi ini dapat merugikan kesehatan manusia karena jika terkena panas sedikit saja, gasnya dapat menyebar di udara. Jika emisi 
formaldehida ini terhirup secara terusmenerus dapat menyebabkan penyakit kanker dan gangguan pada sistem pernapasan.

Oleh sebab itu untuk mengurangi emisi formaldehida yang tidak ramah terhadap kesehatan, digunakan daun lamtoro (Leucaena Leucocephala) yang mengandung polifenol alam yaitu tanin sebagai pengganti urea formaldehida. Senyawa tanin yang terkandung dalam daun lamtoro dapat digunakan sebagai perekat tambahan (filler) dalam proses perekatan kayu lapis. Selain itu juga dapat meningkatkan nilai ekonomis dari daun lamtoro, serta mengurangi emisi formaldehida dari perekat yang digunakan sehingga lebih aman untuk kesehatan dan ramah lingkungan. Rekayasa atau teknik adalah penerapan ilmu dan teknologi untuk menyelesaikan permasalahan manusia. Hal ini diselesaikan lewat pengetahuan, matematika, dan pengalaman praktis yang diterapkan untuk mendesain objek atau proses yang berguna. Para praktisi teknik professional disebut perekayasa (sarjana teknik).

Proses produksi adalah urutan kegiatan yang harus dilaksanakan dalam usaha untuk menghasilkan barang maupun jasa. Agar proses produksi mencapai titik optimal, maka diperlukan adanya peningkatan produktivitas dengan jalan menambah faktor-faktor produksi. Proses produksi pada sentra atau perusahaan produksi rekayasa merupakan kegiatan yang dilakukan dikawasan kecil yang memiliki ciri tertentu dimana didalamnya terdapat kegiatan proses produksi suatu jenis usaha yang menghasilkan produk unggulan. Dan juga area yang lebih khusus untuk suatu komoditi dalam kegiatan ekonomi yang telah membudaya yang ditunjang oleh prasarana dan sarana untuk berkembangnya produk atau jasa yang terdiri dari sekumpulan pengusaha mikro, kecil, menengah dan koperasi.

\section{Metodologi Penelitian}

Jenis penelitian yang digunakan adalah eksperimen laboratorium dengan pendekatan kuantitatif. Hal ini berdasarkan kepada defenisi dan dari kedua pendekatan, yaitu pendekatan kualitatif dan pendekatan kuantitatif. Kuantitatif yaitu penelitian yang banyak dituntut menggunakan angka, mulai dari pengumpulan data, penafsiran terhadap data tersebut serta penampilan dari hasilnya. Penelitian ini dilakukan di Laboratorium
SMK-SMAK Padang yang beralamat di Jl.Alai Pauh V No 13 Kel. Kapalo Koto, Kec. Pauh Kota Padang Propinsi Sumatera Barat yang dilaksanakan pada bulan Juni 2015.

Populasi dan sampel merupakan objek atau subjek yang dipelajari, akan tetapi populasi menurut Suharimi Arikuto mengemukakan bahwa "Populasi adalah keseluruhan subjek penelitian". Sugiyono mengemukakan bahwa Populasi bukan hanya sekedar jumlah yang ada mencakup keseluruhan dari karakteristik atau sifat yang dimiliki oleh subjek atau objek itu. Populasi dari penelitian ini adalah daun lamtoro berwarna hijau tua. "Sampel adalah sebagian atau wakil yang diteliti". Lebih lanjut Suharsimi Arikunto mengemukakan bahwa apabila subjek penelitian kurang dari 100, maka lebih baik diambil semua sehingga penelitiannya merupakan penelitian populasi, namun apabila subjeknya besar atau lebih dari 100, maka dapat diambil antara $10-15 \%$ atau 20-25\% atau lebih. Sampel pada penelitian ini adalah $2 \mathrm{Kg}$ daun lamtoro kering warna hijau tua. Untuk menjawab kasus diatas perlu diteliti dengan menggunakan parameter sebagai berikut :

1. Proses pembuatan yaitu penarikan senyawa tanin dengan metoda ekstraksi.

2. Kualitas dari perekat digunakan beberapa parameter uji sesuai SNI 06-0060-1987.

3. Biaya produksi dari perekat yaitu dengan menghitung Total biaya yang dikeluarkan untuk membuat 1 kilogram perekat.

Jenis data yang digunakan yaitu data primer. Data primer adalah data yang diperoleh atau dikumpulkan langsung di lapangan. Sumber data diperoleh melalui Uji laboratorium seperti : Uji Kenampakan (Film) seperti bentuk, warna, Uji $\mathrm{pH}$ yaitu nilai $\mathrm{pH}$, Uji Viskositas yaitu kekentalan, berat jenis (BJ), Kadar zat padat, waktu gelatinasi, masa simpan dan keteguhan rekat dari perekat kayu lapis dari daun lamtoro, serta data dari proses pembuatan perekat dan data analisis biaya produksi perekat kayu lapis dari daun lamtoro.

Teknik pengolahan dan analisa data pada penelitian ini menggunakan beberapa tahapan antara lain pada proses pembuatan perekat, Uji kualitas perekat dan Biaya produksi dari perekat kayu lapis dari daun lamtoro, langkah yang dilakukan adalah sebagai berikut : 
Dimana dalam pembutan perekat kayu lapis dari daun lamtoro digunakan prosedur sebagai berikut :

a. Prosedur penarikan senyawa tanin yang terkandung dalam daun lamtoro secara Ekstraksi yaitu :

1. Bahan baku utama yaitu daun lamtoro yang berwarna hijau tua

2. Daun lamtoro berwarna hijau tua yang masih dalam kondisi basah, dikering (tidak dibawah matahari)

3. Setelah kering daun lamtoro tersebut dihaluskan dengan blender

4. Kemudian daun lamtoro diambil kandungan senyawa tanin dengan cara Ekstrasi yaitu perendaman selama 2-5 jam dengan air panas suhu $70{ }^{\circ} \mathrm{C}$.

5. Kemudian hasil ekstraksi disaring untuk memisahkan filtrat dari ampas daun lamtoro.

6. Filtrat hasil saringan daun lamtoro diuapkan sampai menjadi pekat.

7. Filtrat atau hasil ekstraksi yang sudah dipekatkan selanjutnya digunakan untuk pembuatan perekat.

b. Prosedur pembuatan perekat

1. Siapkan semua alat dan bahan yang akan digunakan.

2. Timbang ekstrak daun lamtoro sebanyak $77 \%$

3. Campur dengan kasein 25 gram dan trietanolamin dan air dingin, aduk hingga membentuk pasta.

4. Tambahkan lagi sedikit air dingin aduk hingga homogen dan panaskan lagi diatas penangas air suhu $100{ }^{\circ} \mathrm{C}$ sambil diaduk terus hingga perekat mengental. Jika sudah kental keluarkan dari penangas air .

5. Dinginkan selama \pm 20 menit dan masukkan ke dalam wadah yang telah disiapkan.

Data pengujian kualitas dari perekat kayu lapis dari daun lamtoro, diperoleh data dari pengujian parameter sebagai berikut :

1. Uji Kenampakan (Film)

2. Pengujian $\mathrm{pH}$

3. Uji Kekentalan (Viskosity)

4. Penentuan Kadar Zsat Padat

5. Berat Jenis

6. Uji Waktu Gelatinasi

7. Uji Masa Simpan

8. Uji Keteguhan Rekat
1. Uji Kenampakan (Film)

1. Contoh perekat dituangkan di atas permukaan kaca datar, lalu dialirkan sampai membentuk lapisan tipis.

2. Dilakukan pengamatan visual tentang warna, tekstur, tacky dan keberadaan benda asing berupa butiran padat, debu dan benda lain.

2. Pengecekan $\mathrm{pH}$ menggunakan kertas $\mathrm{pH}$ universal

1. Celupkan kertas $\mathrm{pH}$ universal ke dalam contoh perekat yang akan diukur.

2. Angkat dan bandingkan warna kertas $\mathrm{pH}$ universal dengan warna pada standar warna $\mathrm{pH}$ universal.

3. Bila terdapat kesamaan warna pada standar tertentu maka $\mathrm{pH}$ perekat sama dengan nilai $\mathrm{pH}$ yang ditunjukkan pada standar tersebut.

3. Pengujian Viskosity (Kekentalan menggunakan Viskometer metoda bola Jatuh)

1. Ukurlah diameter bola kaca dengan mikrometer

2. Tentukan batas atas (sekitar $10 \mathrm{~cm}$ dari permukaan zat cair)

3. Tentukan batas bawah (sekitar 60-80 cm dari batas atas)

4. Jatuhkan bola dari permukaan zat cair

5. Ukurlah waktu turun bola mulai dari baras atas sampai batas bawah menggunakan stopwatch

6. Ulangi untuk setiap sampel perekat sebanyak 4 kali

4. Pengukuran Berat Jenis (Specific Gravity)

1. Pastikan semua alat yang digunakan dalam keadaan bersih dan kering.

2. Timbang gelas ukur kosong secara teliti. Catat hasil penimbangannya.

3. Isi aquades ke dalam gelas ukur hingga volume $50 \mathrm{ml}$

4. Timbang gelas ukur yang berisi aquades secara teliti. Catat hasil penimbangan.

5. Masukkan sampel perekat yang akan di uji ke dalam gelas ukur tadi hingga volume $50 \mathrm{ml}$.

6. Timbang gelas ukur yang berisi sampel secara teliti. Catat juga hasil penimbangan.

7. Hitung berat jenis sampel dari data yang diperoleh. 
5. Penentuan Kadar Zat Padatan (Metoda Gravimetri)

1. Panaskan cawan kosong yang telah dibersihakan di dalam oven pada suhu $150{ }^{\circ} \mathrm{C}$ selama $1 \mathrm{jam}$.

2. Dinginkan dalam desikator selama 15 menit hingga suhunya sama dengan suhu ruangan.

3. Timbang cawan kosong tersebut secara teliti dan catat hasil penimbangan.

4. Timbang sampel sebanyak $1,5000-$ 2,0000 g, catat hasil penimbangan.

5. Masukkan sampel beserta cawan kedalam oven pada suhu $150^{\circ} \mathrm{C}$ selama $1 \mathrm{jam}$.

6. Dinginkan dalam desikator selama 15 menit hingga suhunya sama dengansuhu ruangan.

7. Timbang cawan beserta sampel yang telah dipanaskan, kemudian catat hasil penimbangan.

8. Lakukan hingga didapatkan berat konstan. Hitung kadar padatan yang diperoleh.

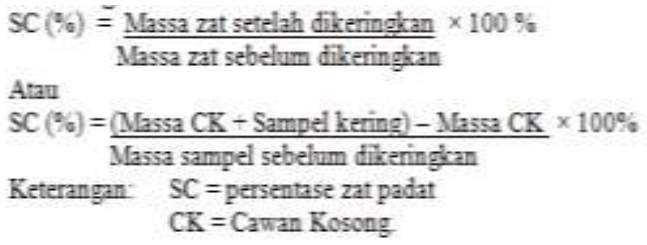

6. Uji Waktu Gelatinasi

1. Masukkan \pm 10 gram contoh perekat ke dalam tabung reaksi.

2. Selanjutnya dipanaskan di atas penangas air pada suhu $100{ }^{\circ} \mathrm{C}$ dengan posisi permukaan perekat berada $2 \mathrm{~cm}$ di bawah permukaan air.

3. Amati waktu yang dibutuhkan perekat tersebut untuk berubah wujud menjadi gel (gelatinasi) dengan cara memiringkan tabung reaksi.

4. Perekat yang sudah tergelatinasi ditandai dengan tidak mengalirnya perekat ketika tabung reaksi dimiringkan.

7. Uji Masa Simpan

1. Masukkan perekat yang telah dibuat kedalam botol dan disimpan.

2. Dicek kondisi sampel setiap hari dengan memperhatikan perubahan $\mathrm{pH}$, warna, bau, endapan dan separasi. Lakukan pengecekan selama \pm 2 minggu.
8. Uji Keteguhan Rekat

a. Disiapkan beberapa lembaran vinir.

b. Oleskan perekat yang akan diuji daya rekatnya dengan menggunakan kuas pada beberapa lembaran vinir tersebut, lalu ditempelkan dengan lembaran vinir lainnya.

c. Lakukan press dingin selama 30 menit, setelah itu tunggu selama 1525 menit. Selanjutnya dilakukan uji keteguhan rekat dengan membuka lembaran vinir yang sudah direkatkan tersebut.

d. Lakukan juga press panas dengan suhu $110{ }^{\circ} \mathrm{C}$ selama \pm 30 menit,setelah itu tunggu selama 2 hari. Selanjutnya dilakukan uji keteguhan rekat dengan membuka lembaran vinir yang sudah direkatkan tersebut.

\section{Biaya Produksi Perekat Kayu Lapis dari Daun Lamtoro}

Biaya produksi dapat diketahui, dengan menentukan biaya-biaya sebagai berikut :

a. Biaya tetap

Biaya tetap merupakan biaya yang dikeluarkan relatif sama walaupun volume preoduksi berubah-ubah dalam batas waktu tertentu, yang menjadi biaya tetap dalam penelitian ini yaitu gaji pimpinan dan karyawan, biaya perbaikan dan perawatan, premi asuransi, biaya operasi kantor, dan biaya umum.

b. Biaya Variabel

Biaya Variabel merupakan biaya yang besarnya berubah secara proporsional dengan jumlah produksi yang dibuat, yang menjadi biaya variabel dalam pembuatan perekat kayu lapis dari daun lamtoro ini berupa biaya bahan baku, bahan pembantu, biaya operasional pabrik, upah, bahan bakar kendaraan, biaya pembungkusan dan biaya transportasi.

Biaya produksi merupakan total biaya tetap ditambah total biaya variabel pada jangka waktu tertentu, sedangan untuk menentukan harga pokok produksi diperoleh dari Total biaya produksi per jumlah unit produksi dalam jangka waktu tertentu. 


\section{Hasil Penelitian Dan Pembahasan}

Dari hasil penelitian pembuatan perekat dari daun lamtoro diperoleh analisa sebagai berikut :

3.1 Analisa proses pembuatan perekat kayu lapis dari daun lamtoro

Pada proses pembuatan perekat kayu lapis dari daun lamtoro dibutuhkan waktu mulai dari pengumpulan bahan, proses pengeringan, ekstrasi dan pembuatan perekat dibutuhkan waktu yaitu 5 hari, dimana untuk proses pengeringan (tidak dibawah matahari langsung) 3 hari , untuk mengekstrak daun lamtoro 1 hari, dan untuk proses pembuatan perekat 2 jam, jadi total waktu yang dibutuhkan adalah \pm 5 hari.

\subsection{Analisa kualitas perekat kayu lapis dari daun lamtoro}

Untuk Analisa kualitas perekat kayu lapis dari daun lamtoro dapat dilihat dari hasil uji beberapa parameter yang dilakukan terhadap perekat, dari delapan parameter uji kualitas berikut:

1. Uji $\mathrm{pH}$ diperoleh $\mathrm{pH}$ perekat daun lamtoro 6,8 sesuai dengan standar Industri Indonesia yaitu $6,5-10,5$.

2. Uji kekentalan (Viskositas) diperoleh kekentalan perekat kayu lapis dari daun lamtoro yaitu rata-rata 1973,72 cps memenuhi standar SNI 06-0060-1987 yaitu $1100-2200$ cps.

3. Uji Berat jenis perekat daun lamtoro mempunyai berat jenis rata-rata 1,0748 $\mathrm{gr} / \mathrm{ml}$, tidak sesuai dengan standar SNI 060060-1987 yaitu berat jenis pada standar 0,40 - 0,90 gr/ml. Disebabkan karena perekat terlalu kental sehingga besar dari Berat jenis air yaitu $1 \mathrm{~g} / \mathrm{ml}$, solusinya supaya perekat dibuat dalam bentuk cairan.

4. Uji kenampakan terhadap perekat kayu lapis dari daun lamtoro sebagai berikut :

a. Warna dari perekat Coklat kehijau sesuai dengan sehingga perekat tidak menimbulkan warna lain pada lapisan kayu.

b. Bau, perekat kayu lapis dari daun lamtoro tidak memiliki bau yang menyengat.

c. Waktu yang dibutuhkan perekat untuk kering yaitu 6 menit, semakin cepat waktu yang diperlukan perekat untuk kering, semakin bagus perekat tersebut.
5. Kadar Zat Padat, dari hasil pengujian zat padat pada perekat kayu lapis dari daun lamtoro memiliki kadar yang rendah yaitu rata-rata $21.77 \%$, ini disebabkan karena bahan dasar pembuatan perekat dari ektrak daun lamtoro, kasein dan trietanolamin yang mengandung air, sehingga untuk kadar zat padat tidak sesuai standar. Pada standar min $60 \%$, untuk meningkatkan zat padat digunakan serbuk daun lamtoro dalam pembuatan perekat bukan ekstraknya.

6. Uji waktu gelatinansi pada perekat kayu lapis dari daun lamtoro diperoleh waktu gelatinasi rata-rata 38 menit sesuai dengan standar SNI yaitu $\geq 30$ menit.

7. Uji keteguhan rekat dan masa simpan

Dari hasil uji daya rekat yang dilakukan pada lapisan vinir, daya rekat dari perekat kayu lapis dari daun lamtoro cukup kuat ini juga dipengaruhi oleh kekentalan dari perekat tersebut dan untuk masa simpan yaitu 1 bulan, dimana perekat belum mengalami

perubahan warna, bau, $\mathrm{pH}$ dan daya rekat. setelah lewat 1 bulan perekat mengalami perubahan bau yang kurang sedap dan perekat mulai mengumpal, $\mathrm{pH}$ mengalami penurunan menjadi semakin rendah. Hal tersebut menunjukan telah terjadi kerusakan pada perekat.

\subsubsection{Analisa Biaya produksi perekat kayu lapis dari daun lamtoro}

Untuk memproduksi $1100 \mathrm{Kg}$ perekat setiap bulannya diperoleh total biaya produksi pada pembuatan perekat kayu lapis dari daun lamtoro ini adalah sebesar Rp.20.788.322,-Sehingga diperoleh harga pokok produksi sebesar Rp.18.898,-/Kg perekat kayu lapis dari daun lamtoro.

Sementara harga ekstrak gambir yang digunakan sebagai perekat kayu lapis yang dijual dipasaran yaitu $\mathrm{Rp} 8.000 \mathrm{~s} / \mathrm{d} \quad \mathrm{Rp}$ $30.000 / \mathrm{kg}$ menurut sumber pinangiris blogspot. Harga pokok perekat kayu lapis dari daun lamtoro sebanding dengan harga ekstrak gambir yang akan diolah untuk menjadi perekat kayu lapis, Jadi harga pokok perekat kayu lapis dari daun lamtoro lebih rendah dari perekat ekstrak gambir. 
4. Kesimpulan

1. Untuk proses pembuatan perekat kayu lapis dibutuhkan waktu 5 hari, warna coklat kehijauan.

2. Kualitas perekat kayu lapis dari daun lamtoro cukup bagus sesuai standar SNI 06-0060-1987.

3. Biaya produksi perekat kayu lapis dari daun lamtoro per bulan adalah $\mathrm{Rp}$. 20.788.322,-untuk $1100 \mathrm{~kg}$ perekat dan harga pokok produksi sebesar Rp. $18.898,-$ / kg perekat kayu lapis dari daun lamtoro.

\section{DAFTAR PUSTAKA}

Badan Standarisasi Nasional, "SNI 06-00601987 tentang "Urea Formaldehida

Cair untuk Perekat Kayu Lapis", BSN, Jakarta, 1987.

Bresnick Stephen, M.D, Intisari Kimia

Organik, Erlangga, Jakarta, 2003.

Halim Abdul , Akuntansi Biaya, BPFE, Yogyakarta, 2009.

Haryobrono, Memanfaatkan akasia sebagai perekat, 2010

http://haryobrono.blogspot.com/2010/1

1/memanfaatkan-akasia-sebagai perekat.htm, diakses 27 Mei 2015

Iskandar, Herman, Buku Pedoman Produk dan Teknik Perekat. Jakarta, 1992

Kustiawan, Lamtoro, (online). http:id.wikipedia.org/wiki/Lamtoro. diakses pada 5 April 2015.

Khopkar, Konsep Dasar Kimia Analitik, Universitas Indonesia, Jakarta, 2003

Kotler, Philip, "Marketing Management, Analisis, Planing and Control", Englewood Chiffs N.J : Phi, 1986, 5 Th Edition, Terjemahan Wasara, Jaya, "Manajemen Pemasaran, Analisis, Perencanaan dan Pengendalian", Edisi ke V, Jilid 1:Erlangga Jakarta, 1987.

Mulyadi, Akuntasi Biaya,YKPN, Yogyakarta 2005.

Permanasari Anna, dkk, Kimia Analitik 2,

Universitas Terbuka, Jakarta, 2007

Sumarsono, Sonny, Ekonomi Mikro: teori dan soal latihan, Graha Ilmu, Yogyakarta, 2006

Tano, Eddy, Pedoman Pembuatan Perekat

Sintetis, Rineka Cipta, Jakarta, 1997. 
